\title{
Quantitative Analysis of Factors Influencing Heat Dissipation in a Metal-Plastic Composite Heat Radiator with a Hemispherical Microstructure Array
}

\author{
H. Jiang, ${ }^{1,2}$ J. Zhuang, ${ }^{1,2}$ Y. Liu, ${ }^{1,2,3}$ Z. L. Zhao, ${ }^{1,2}$ and D. M. Wu ${ }^{1,2,3}$ \\ ${ }^{1}$ College of Mechanical and Electrical Engineering, Beijing University of Chemical Technology, Beijing 100029, China \\ ${ }^{2}$ Polymer Material Processing Equipment Engineering Research Center of the Ministry of Education, Beijing 100029, China \\ ${ }^{3}$ State Key Laboratory of Organic-Inorganic Composites, Beijing University of Chemical Technology, Beijing 100029, China \\ Correspondence should be addressed to D. M. Wu; wudaming@vip.163.com
}

Received 30 November 2014; Accepted 26 December 2014

Academic Editor: Francesco Tornabene

Copyright (C) 2015 H. Jiang et al. This is an open access article distributed under the Creative Commons Attribution License, which permits unrestricted use, distribution, and reproduction in any medium, provided the original work is properly cited.

\begin{abstract}
A metal-plastic composite heat radiator with a hemispherical microstructure array was studied. A quantitative analysis was carried out for various factors that influence the radiator. The ratio of microstructure area, the heat generated by the heat source, the thermal conductivity of plastic, radiant emissivity of the plastic, the surface convection coefficient, and the environmental temperature were included in the analysis. The results suggested that we could achieve the exact influence size on the temperature of heat source.
\end{abstract}

\section{Introduction}

With the development of micromechanical systems and microchemical mechanical systems, the heat produced by multifunctional and complex systems has greatly increased and the thermal environment has become increasingly harsh. Conventional heat exchanger units cannot meet the basic requirements of high efficiency, heat stability, and low processing cost. The traditional heat exchanger is made of metal or silicon, which leads to high processing costs and a difficult process. There are two ways to improve the performance of the heat exchanger: modifying the composite material and structural optimization.

Heat exchangers are commonly made of a metal with a relatively high thermal conductivity, such as aluminum and copper. However, the metal heat exchanger has a high processing cost, the processing cycle is relatively long, processing efficiency is relatively low, and the weight of the metal heat exchanger is very heavy. Prior efforts have attempted to use polymers in the heat exchanger, but their low thermal conductivity results in a drop in the thermal efficiency by several orders of magnitude. Attempts have been made [13 ] to enhance the thermal conductivity of the polymer by blending in metals and inorganic nonmetallic. However, due to the large interfacial thermal resistance between the polymer body and the packing material, the increase in thermal conductivity is limited. When the volume fraction of fillers was increased, the mechanical properties and processing properties of the polymer matrix composites were affected and thermal conductivity could only reach approximately $25 \mathrm{~W} / \mathrm{m} \cdot \mathrm{K}$. Zhou [4] used compression molding to put AlN (aluminium nitride) into linear low-density polyethylene (LLDPE) to prepare a composite material with a thermal conductivity of $1.25 \mathrm{~W} / \mathrm{m} \cdot \mathrm{K}$ and a thermal stability that is higher than that of pure LLDPE. Tu and Ye [5] incorporated graphite into polystyrene (PS) to prepare graphite/PS nanocomposites. When $\varphi=34 \%$ for colloidal graphite, its thermal conductivity increases to $1.95 \mathrm{~W} / \mathrm{m} \cdot \mathrm{K}$. Yu and Hing [6] used melt blending to prepare a composite filled with carbon fiber, glass fiber, PS, and alumina. Since the carbon fiber is more likely to form thermal networks deep within the polymer, the thermal conductivity of the carbon fiber/PS composite increases to $27 \mathrm{~W} / \mathrm{m} \cdot \mathrm{K}$. Although a number of methods have been adopted to greatly increase the thermal conductivity of polymers, it is still difficult to form a continuous thermal network within the polymer. Additionally, there 
is still a large gap between the thermal effects of the modified polymers and metals. This has made it difficult to create a suitable alternative to metals.

The use of fine structures has resulted in the introduction of compact heat exchangers. The volumetric heat transfer coefficient can be as high as several tens to several hundreds of $\mathrm{MW} / \mathrm{m}^{3} \cdot \mathrm{K}$. Compared with the conventional heat exchanger, this is five orders of magnitude higher $[7,8]$. At the same time, the compact heat exchanger boasts several other advantages such as a high heat transfer efficiency, a compact structure, low weight, and safe and reliable operation. Rezania and Rosendahl [9] optimized the microstructure geometry of a compact aluminum heat exchanger to reduce the thermal resistance of the heat exchanger. The cooling fluid flow is reduced, thereby reducing the cooling flow pump power consumption. Basuki et al. [10] studied the solid phase diffusion bonding method of a nickel alloy C-22 microstructure heat exchanger to obtain better tensile strength and stiffness in the microstructure. Due to the limitations of traditional processing methods, silicon and metal heat exchangers have high processing costs and low processing efficiency. The polymer microstructure fins are only conducive to heat dissipation. They can be used in specific applications but their thermal conductivity restricts their application outside of those regimes.

Efforts have been made to improve the heat transfer performance of modified polymeric materials or to increase the heat transfer area to improve the heat transfer efficiency of the microstructure heat exchanger. However, it has proved difficult to further enhance the heat transfer using these methods alone, which has led to an exploration of using both. Harris et al. [11] studied the heat transfer characteristics of aluminum, ceramic, and polymer microstructures in a crossflow heat exchanger. Test results are displayed in air pressure and coolant under the same pressure conditions, and the heat flow of polymer material microstructure heat exchanger can obtain cooling effect similar to the metal and ceramic. Bahadur and Bar-Cohen [12] and Han et al. [13] studied the plastic radiator cooling effect. The results indicate that the plastic radiator can replace the metal radiator in certain situations. However, the plastic radiator has low thermal conductivity and large thermal resistance. Heat cannot be quickly or effectively transmitted from the heat source to the surface of the microstructure. This restricts the heat transfer efficiency and results in low market potential.

In summary, the metal microstructure heat exchanger has high processing costs and polymers have a low thermal conductivity. The technology has therefore reached its limits and there is a need to develop new methods and innovative designs. In this paper, a new composite structure micro heat exchanger is introduced that uses a metal substrate as the conductive element and a plastic with microstructures as the dissipative unit. The factors that influence the metal-plastic composite heat radiator with a hemispherical microstructure array were analyzed.

\section{A Metal-Plastic Composite Heat Radiator with a Hemispherical Microstructure}

The metal-plastic composite heat radiator with a hemispherical microstructure array is made up of three layers, as shown in

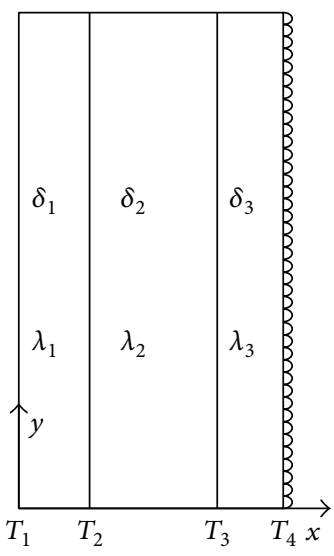

FIGURE 1: Schematic of a metal-plastic composite heat radiator with a hemisphere microstructure array.

Figure 1. The first layer is the heat source, which could be high-power electronics or LEDs. The heat generated needs to be dissipated as soon as possible. The first layer is heat source. The thermal conductivity is $\lambda_{1}$, and the thickness is $\delta_{1}$. When $x=0$, the surface contact temperature is $T_{1}$. When $x=\delta_{1}$, the temperature is $T_{2}$, the thermal conductivity is $\lambda_{2}$, and the thickness is $\delta_{2}$. When $x=\delta_{1}+\delta_{2}$ and the contact temperature with the third layer is $T_{3}$, the third layer is the conductive plastic where the thermal conductivity is $\lambda_{3}$ and the thickness is $\delta_{3}$. When $x=\delta_{1}+\delta_{2}+\delta_{3}$, the surface area is increased by the addition of the microstructure. The surface temperature is $T_{4}$. On the surfaces, $B_{i}=(\delta h / \lambda) \leq 0.1$, and therefore, the temperature on the left of the microstructure is the same as that on the right surface of the third layer. The convective heat transfer coefficient is given by

$$
Q=h A\left(T_{4}-T_{f}\right)
$$

Therefore, an increase in the area can increase the heat transfer.

\section{Mathematical Model}

Model Assumptions

(1) The solid materials are isotropic.

(2) The roughness of the contact surface is ignored. This means that the thermal resistances between heat source and metal diffuser and between the metal diffuser and conductive plastic are ignored.

(3) The heat transfer at each surface exposed to the air is governed by natural convection.

(4) Since the plastic and metal layers and heat source are thin, the convection and radiation heat loss on the side surface are ignored.

(5) The model can be simplified as an infinite flat wall for heat conduction and dissipation. In other words, the temperature and heat flux is homogeneous at each point in a given cross section. 
TABLE 1: Physical parameters of the different materials.

\begin{tabular}{lccccc}
\hline Material & Density $\left(\mathrm{kg} / \mathrm{m}^{3}\right)$ & Specific heat $(\mathrm{J} / \mathrm{kg} \cdot \mathrm{K})$ & $\begin{array}{c}\text { Thermal conductivity } \\
(\mathrm{W} / \mathrm{m} \cdot \mathrm{K})\end{array}$ & $\begin{array}{c}\text { Types of thermal } \\
\text { conductivity }\end{array}$ & Melting temperature $(\mathrm{K})$ \\
\hline Aluminum 6061 & 2688.9 & 902 & 237 & Isotropic & 855 \\
PPS & 1800 & 1100 & 20 & Isotropic & 573 \\
Air & 1.205 & 1006.43 & 0.02637 & Isotropic & - \\
\hline
\end{tabular}

(6) The heat source on the left side could be regarded as adiabatic.

Let $Q$ represent the entire heat loss through the radiator. On the surface of conductive plastic microstructure, the convective heat transfer coefficient is denoted by $h$. The radiant emissivity of conductive plastic is denoted by $\varepsilon$. The physical parameters of the different materials are listed in Table 1. $T_{h}, T_{m}$, and $T_{p}$ stand for the temperature of heat source, metal layer, and plastic layer, respectively. According to the energy conservation and the Fourier law, we can get the following equations.

When the radiator achieved heat balance, we have the following:

$$
\text { When } x=0, \quad Q=-\lambda_{1} A_{1} \frac{d T_{h}}{d x} .
$$

The heat transfer from the heat source to the metal diffuser is given by

$$
\text { When } x=\delta_{1}, \quad-\lambda_{1} A_{1} \frac{d T_{h}}{d x}=-\lambda_{2} A_{1} \frac{d T_{m}}{d x} .
$$

The heat transfer from the metal diffuser to thermally conductive plastic layer is given by

$$
\text { When } x=\delta_{1}+\delta_{2}, \quad-\lambda_{2} A_{1} \frac{d T_{m}}{d x}=-\lambda_{3} A_{1} \frac{d T_{p}}{d x} .
$$

The heat transfer between the thermally conductive plastic layer and the environment is given by

$$
\begin{aligned}
& \text { When } x=\delta_{1}+\delta_{2}+\delta_{3} \text {, } \\
& -\lambda_{3} A_{1} \frac{d T_{p}}{d x}=h A_{2}\left(T_{4}-T_{f}\right)+A_{2} \varepsilon \sigma\left(T_{4}^{4}-T_{f}^{4}\right) .
\end{aligned}
$$

Let the above equations be discretized approximately. We can get the following simplified equations:

$$
\begin{aligned}
& \text { When } x=0, \quad Q=-\lambda_{1} A_{1} \frac{T_{2}-T_{1}}{\delta_{1}}, \\
& \text { When } x=\delta_{1}, \quad-\lambda_{1} A_{1} \frac{T_{2}-T_{1}}{\delta_{1}}=-\lambda_{2} A_{1} \frac{T_{3}-T_{2}}{\delta_{2}}, \\
& \text { When } x=\delta_{1}+\delta_{2}, \quad-\lambda_{2} A_{1} \frac{T_{3}-T_{2}}{\delta_{2}}=-\lambda_{3} A_{1} \frac{T_{4}-T_{3}}{\delta_{3}},
\end{aligned}
$$

When $x=\delta_{1}+\delta_{2}+\delta_{3}$,

$$
-\lambda_{3} A_{1} \frac{T_{4}-T_{3}}{\delta_{3}}=h A_{2}\left(T_{4}-T_{f}\right)+A_{2} \varepsilon \sigma\left(T_{4}^{4}-T_{f}^{4}\right) .
$$

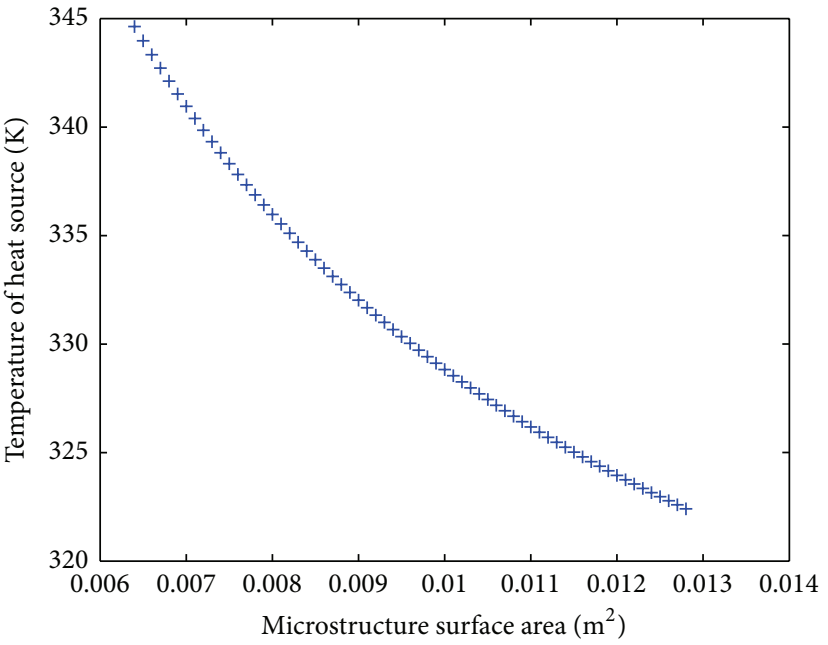

FIGURE 2: The relationship between the temperature of heat source and microstructure surface area.

There are therefore four equations with five unknown parameters: $h, T_{1}, T_{2}, T_{3}, T_{4}$. The others were known conditions. The unknown solutions can therefore be calculated. Using MATLAB, we can calculate the curve in which the factors influence the temperature of heat source $T_{1}$. The better the heat dissipation effect, the lower the temperature.

\section{Results and Discussion}

This study focuses on the effect of varying the temperature of the heat source on the heat transfer characteristics of the heat exchanger. Numerical calculations were performed to determine the effect of adding the hemispherical microstructure array. The surface area is $0.0064 \mathrm{~m}^{2}$ in smooth situation. The addition of the hemispherical array increases the surface area and raises the limit of the area ratio $A_{2} / A_{1}$ from 1 to 2 . When $A_{2} / A_{1}=1$, it represents that the surface is smooth. When $A_{2} / A_{1}=2$, it represents that the surface is full of hemisphere. In Figure 2, the $x$-axis represents the heat source with a constant $Q$ and the $y$-axis represents the temperature of heat source. As shown in Figure 2, as the $Q$ increases, the temperature of the heat source also increases in a nearly linear manner. As the area ratio $A_{2} / A_{1}$ decreases, the gradient increases. When $Q$ is $5 \mathrm{~W}$, the temperature ratio was 1.07 times between the area ratios of 1 and 2 . This is because as $A_{2} / A_{1}$ increased, the heat transfer by radiation from the plastic layer and free convection increases. As a result, the temperature decreased. 


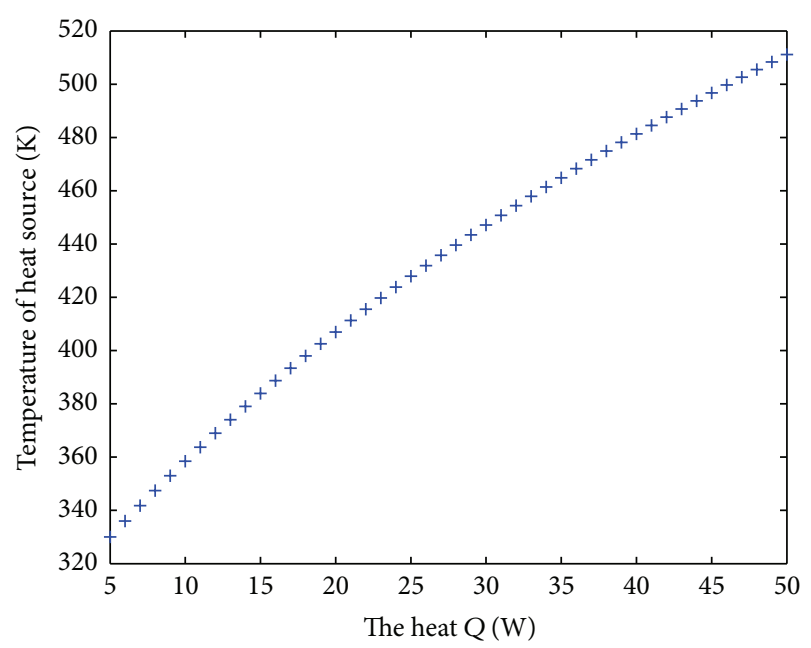

Figure 3: The relationship between the temperature of heat source and the heat $Q$.

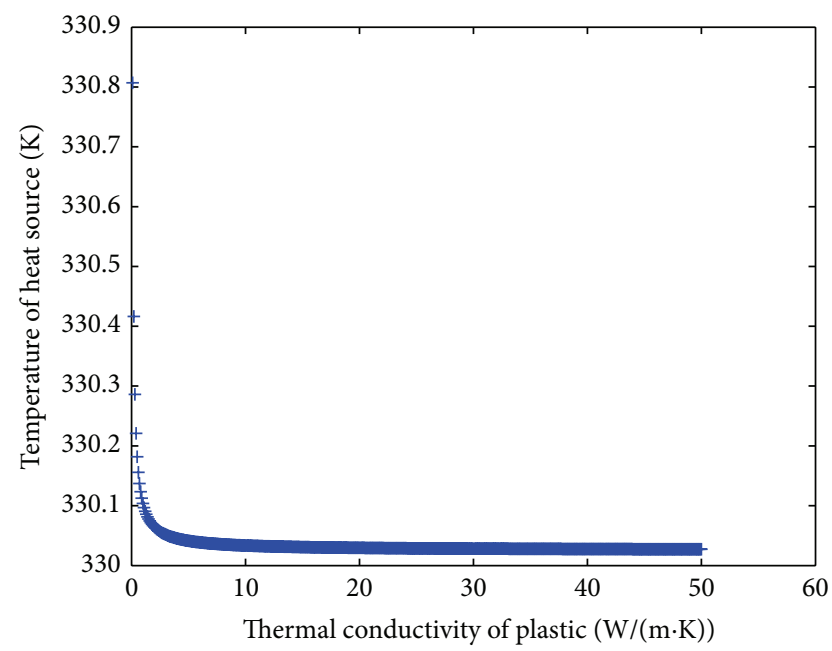

FIgURE 4: The relationship between the temperature of heat source and thermal conductivity of plastic.

The temperature of heat source may also be affected by the heat generated by the heat source. In Figure 3 , the $x$-axis represents the heat $Q$ generated by the heat source and the $y$-axis represents the temperature of the heat source. When $Q$ changes from $5 \mathrm{~W}$ to $50 \mathrm{~W}$, the temperature increases from $330 \mathrm{~K}$ to $510 \mathrm{~K}$. It has increased 1.55 times. In addition, with the change of $Q$, the trend of increase decreases gradually.

As shown in Figure 4, the thermal conductivity coefficient affects the temperature of the heat source. As the thermal conductivity increases, the temperature of the heat source decreases. The temperature of the heat source decreases rapidly as the thermal conductivity coefficient of the plastic changes from $1 \mathrm{~W} / \mathrm{m} \cdot \mathrm{K}$ to $10 \mathrm{~W} / \mathrm{m} \cdot \mathrm{K}$. However, this rapid decrease subsides and the temperature changes more slowly at a thermal conductivity coefficient of approximately $25 \mathrm{~W} / \mathrm{m} \cdot \mathrm{K}$. For higher values, the thermal conductivity coefficient of the plastic has little influence on temperature of

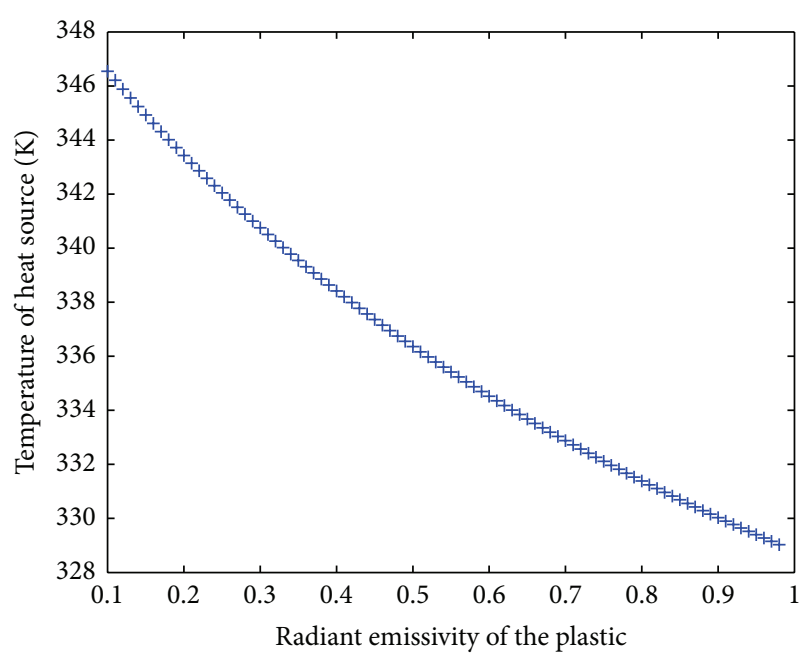

FIGURE 5: The relationship between the temperature of heat source and radiant emissivity of the plastic.

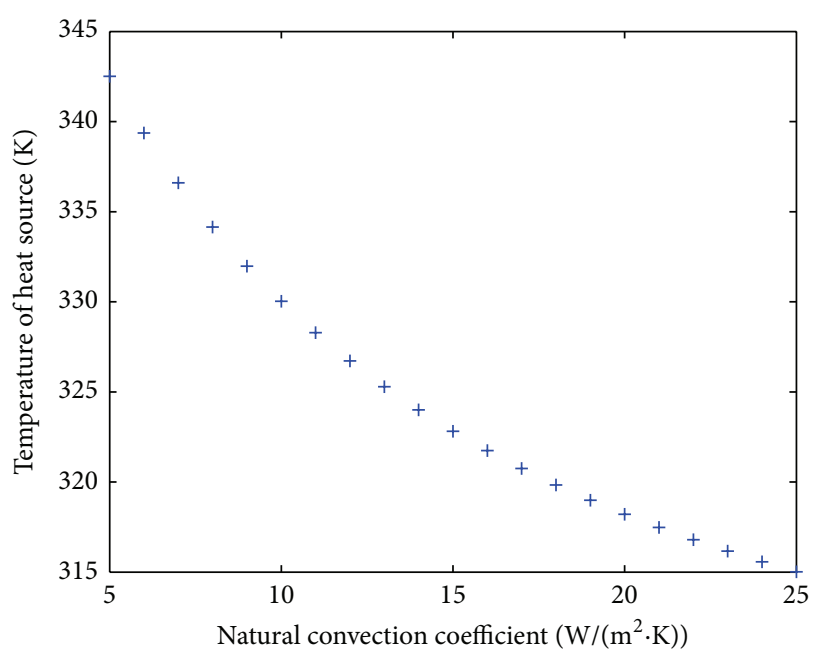

FIGURE 6: The relationship between the temperature of heat source and natural convection coefficient.

the heat source. However, the influence of overall thermal conductivity on the temperature of heat source is also small. This is because the increase of thermal conductivity resulted in a lower thermal resistance, which leads to the overall decrease in temperature.

Figure 5 shows how the temperature varies with radiant emissivity of the plastic. As the radiant emissivity increases, the temperature of heat source reduces gradually and linearly. When the radiant emissivity increases from 0.1 to 0.98 , the temperature of the heat source decreases by approximately $18^{\circ} \mathrm{C}$. For a constant surface area, an increase in the radiant emissivity leads to an increase in radiated heat. This results in a lower temperature at the source.

The surface convection heat transfer also affected the temperature of heat source. The greater the surface convection, the lower the temperature of the heat source. In Figure 6, the $x$-axis represents the surface convection coefficient and 


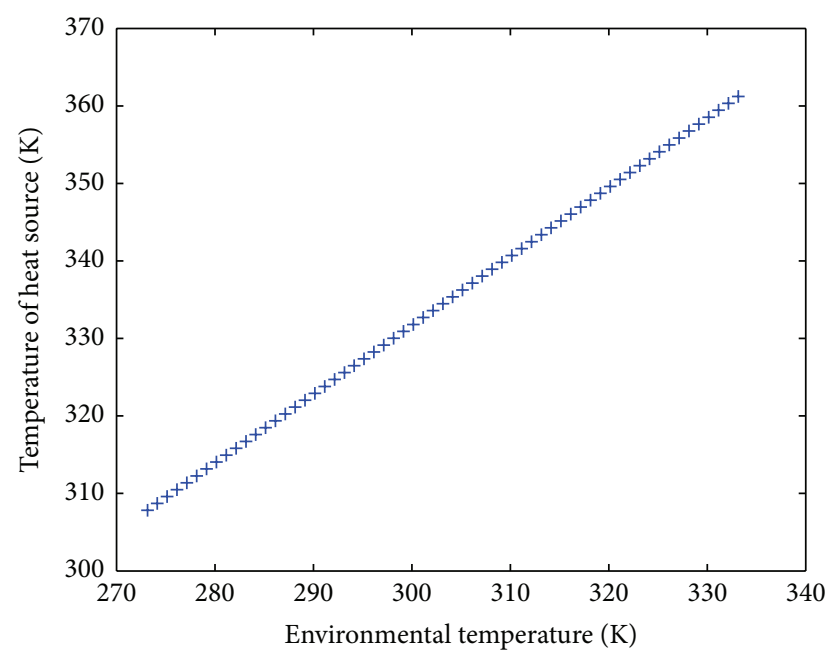

FIGURE 7: The relationship between the temperature of heat source and environmental temperature.

the $y$-axis represents the temperature of the heat source. The changing rule of the temperature of heat source as the natural convection heat transfer coefficient is parabolic curve. The heat transfer coefficient ranged from $5 \mathrm{~W} / \mathrm{m}^{2} \cdot \mathrm{K}$ to $25 \mathrm{~W} / \mathrm{m}^{2} \cdot \mathrm{K}$ with a corresponding drop in the temperature of the heat source from $342 \mathrm{~K}$ to $315 \mathrm{~K}$. This is because for a constant volume, as the convective heat transfer coefficient increases, the heat dissipation increases.

The environmental temperature influenced the temperature of the heat source. The temperature of the heat source increased linearly with the increase in environmental temperature. In Figure 7, the $x$-axis represents the environmental temperature and the $y$-axis represents the temperature of the heat source. As the environmental temperature increased from $298 \mathrm{~K}$ to $324 \mathrm{~K}$, the temperature of the heat source increased from $330 \mathrm{~K}$ to $353 \mathrm{~K}$. The slope of the linear fit was 1.13. In other words, for a $1 \mathrm{~K}$ change in the environmental temperature, the temperature of the heat source changed by $1.13 \mathrm{~K}$. Therefore, the temperature of the heat source changed more quickly than the temperature of the environment.

\section{Conclusions}

A metal-plastic composite heat radiator with a hemispherical microstructure array was introduced in this paper. Factors that influence the heat transfer were studied, namely, microstructure area, the heat generated by the heat source, thermal conductivity coefficient, radiant emissivity of the thermally conductive plastic, natural convection coefficient, and the environmental temperature. The results show the following.

(i) As the ratio of microstructure area to thermally conductive plastic cooling area decreased from 2 to 1 , the temperature of heat source increased by a factor of 1.07 .

(ii) As the heat generated by the heat source changes from $5 \mathrm{~W}$ to $50 \mathrm{~W}$, the temperature increased by a factor of 1.55 . (iii) The coefficient of thermal conductivity of thermally conductive plastic layer had little influence on the junction temperature.

(iv) As the radiant emissivity of the conductive plastic layer changed from 0.1 to 0.98 , the temperature dropped by $18 \mathrm{~K}$.

(v) As the convective heat transfer coefficient changed from $5 \mathrm{~W} / \mathrm{m}^{2} \cdot \mathrm{K}$ to $25 \mathrm{~W} / \mathrm{m}^{2} \cdot \mathrm{K}$, the temperature decreased by $27 \mathrm{~K}$.

(vi) The temperature of the heat source was higher at higher environmental temperature. For a $1 \mathrm{~K}$ change in ambient temperature, the temperature of the heat source changed by $1.13 \mathrm{~K}$.

However, this paper studies only particular size metalplastic composites microstructure heat exchanger. We need to model again and achieve the relation curve for different size Heat Radiator.

\section{Nomenclatures}

$\lambda$ : Thermal conductivity

$\delta$ : Thickness

$T$ : Temperature

$B_{i}$ : The Biot number

$h$ : Surface coefficient of heat transfer

Q: Heat generated by heat source

$\sigma$ : Boltzmann constant

A: Area

$\varepsilon$ : Radiant emittance.

\section{Subscripts}

$f$ : Fluid

$h$ : Heat source

$p$ : Plastic

$m$ : Metal.

\section{Conflict of Interests}

The authors declare that there is no conflict of interests regarding the publication of this paper.

\section{Acknowledgment}

The authors would like to express their gratitude to the National Natural Science Foundation of China Youth Science Fund (no. 51203010).

\section{References}

[1] I. V. Gofman, I. V. Abalov, S. V. Gladchenko, and N. V. Afanas'eva, "Carbon nanocones/discs-a new type of filler to improve the thermal and mechanical properties of polymer films," Polymers for Advanced Technologies, vol. 23, no. 3, pp. 408-413, 2012.

[2] Z. D. Han and A. Fina, "Thermal conductivity of carbon nanotubes and their polymer nanocomposites: a review," Progress in Polymer Science, vol. 36, no. 7, pp. 914-944, 2011. 
[3] E. Chapelle, B. Garnier, and B. Bourouga, "Interfacial thermal resistance measurement between metallic wire and polymer in polymer matrix composites," International Journal of Thermal Sciences, vol. 48, no. 12, pp. 2221-2227, 2009.

[4] W. Y. Zhou, "Thermal and dielectric properties of the AlN particles reinforced linear low-density polyethylene composites," Thermochimica Acta, vol. 512, no. 1-2, pp. 183-188, 2011.

[5] H. M. Tu and L. Ye, "Thermal conductive PS/graphite composites," Polymers for Advanced Technologies, vol. 20, no. 1, pp. 21-27, 2009.

[6] S. Z. Yu and P. Hing, "Thermal and dielectric properties of fiber reinforced polystyrene composites," Polymer Composites, vol. 29, no. 11, pp. 1199-1202, 2008.

[7] P. Gao, S. le Person, and M. Favre-Marinet, "Scale effects on hydrodynamics and heat transfer in two-dimensional mini and microchannels," International Journal of Thermal Sciences, vol. 41, no. 11, pp. 1017-1027, 2002.

[8] Y.-K. Lu, K. Zhao, X.-G. Wang, and H.-F. Liu, "Research on flow and heat transfer characteristics in micro heat exchanger," Advanced Materials Research, vol. 354-355, pp. 684-690, 2012.

[9] A. Rezania and L. A. Rosendahl, "New configurations of micro plate-fin heat sink to reduce coolant pumping power," Journal of Electronic Materials, vol. 41, no. 3, pp. 45-52, 2012.

[10] W. W. Basuki, O. Kraft, and J. Aktaa, "Optimization of solidstate diffusion bonding of Hastelloy C-22 for micro heat exchanger applications by coupling of experiments and simulations," Materials Science and Engineering A, vol. 538, pp. 340348, 2012.

[11] C. Harris, M. Despa, and K. Kelly, "Design and fabrication of a cross flow micro heat exchanger," Journal of Microelectromechanical Systems, vol. 9, no. 4, pp. 502-508, 2000.

[12] R. Bahadur and A. Bar-Cohen, "Thermal design and optimization of natural convection polymer pin fin heat sinks," IEEE Transactions on Components and Packaging Technologies, vol. 28, no. 2, pp. 238-246, 2005.

[13] Y. Han, Y. Zhang, D. Wu, J. Zhuang, and K. Dang, "Optimal design of micro plastic heat radiator," Key Engineering Materials, vol. 503, pp. 67-70, 2012. 


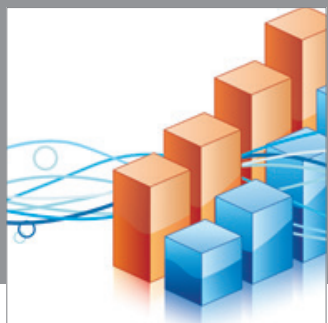

Advances in

Operations Research

mansans

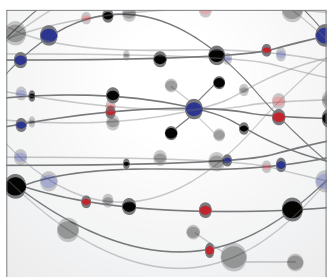

The Scientific World Journal
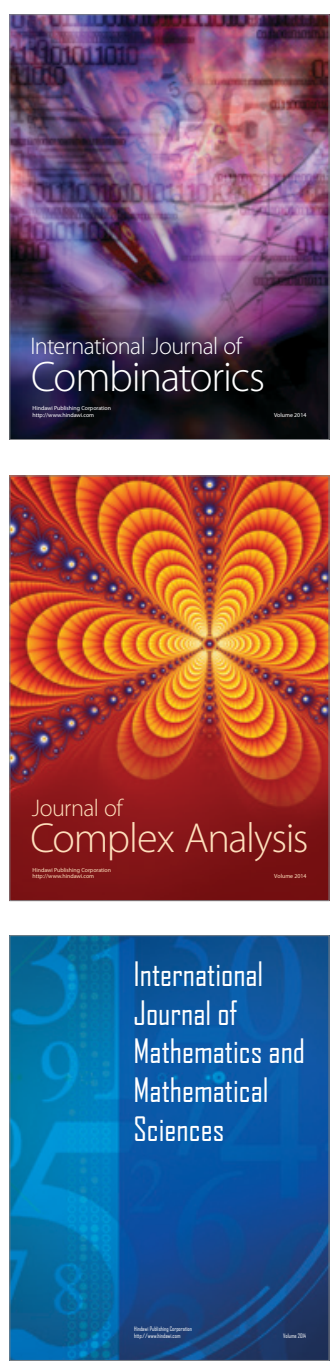
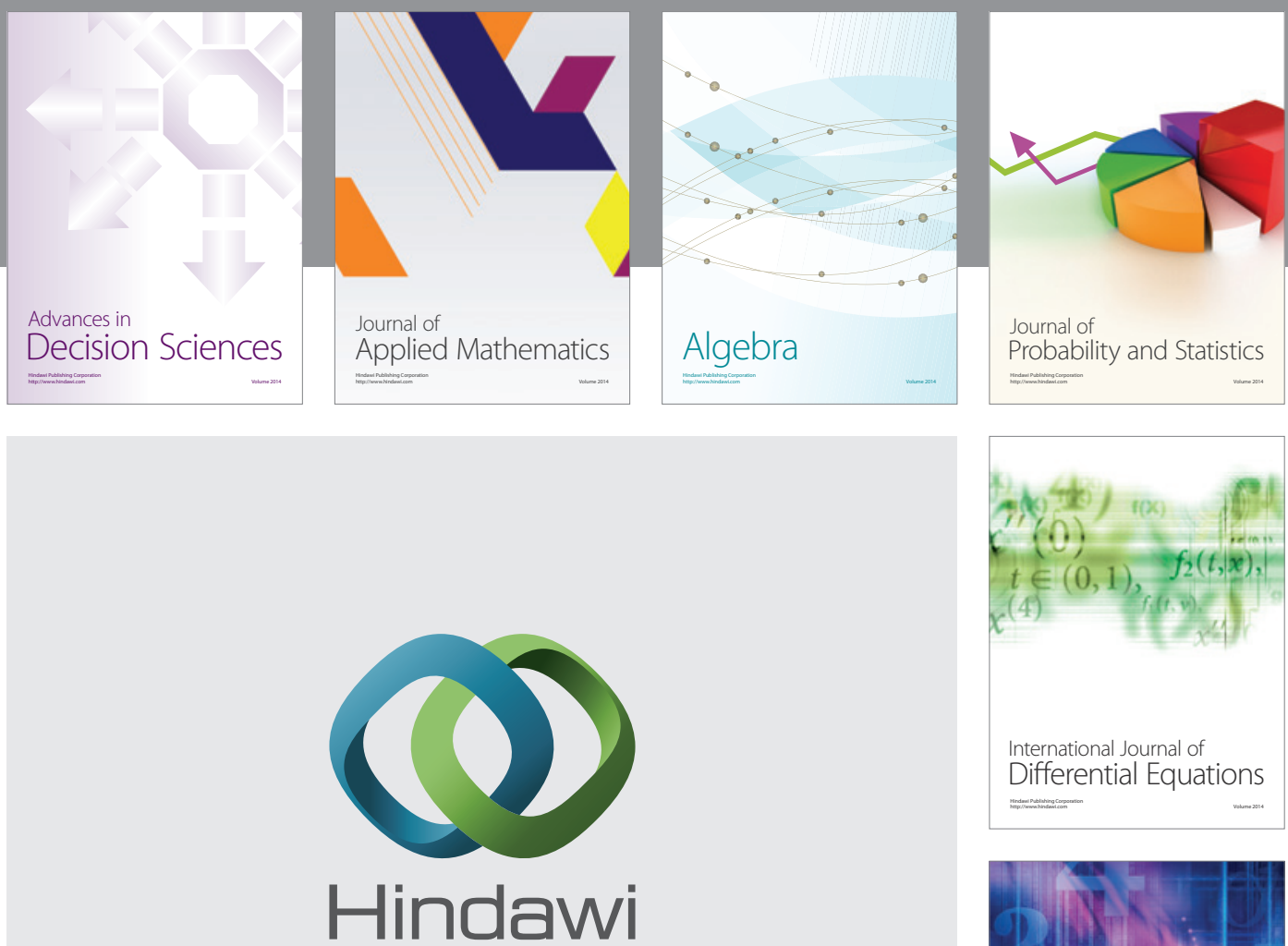

Submit your manuscripts at http://www.hindawi.com
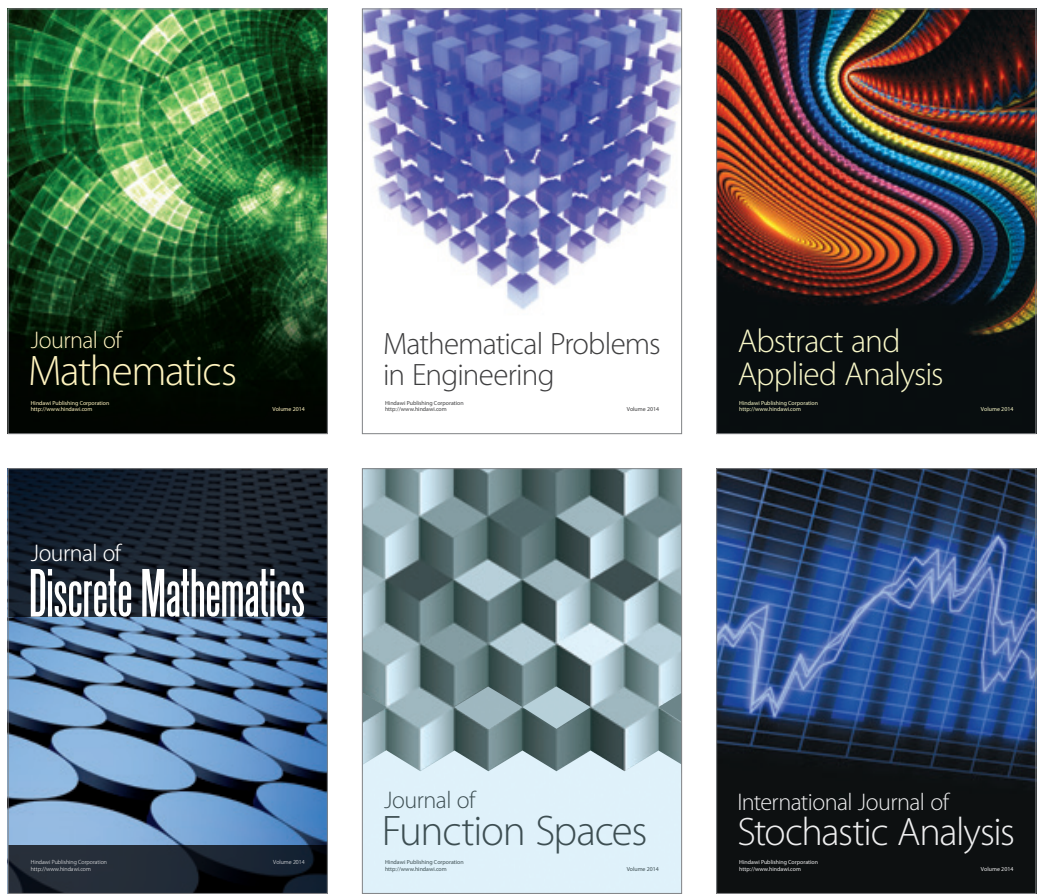

Journal of

Function Spaces

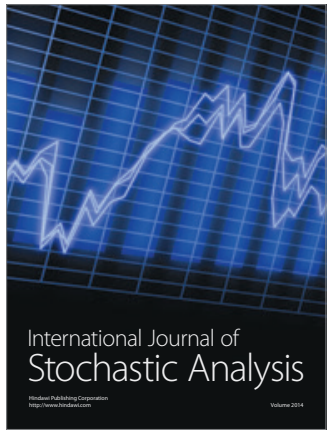

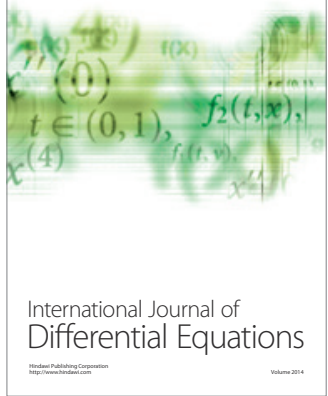
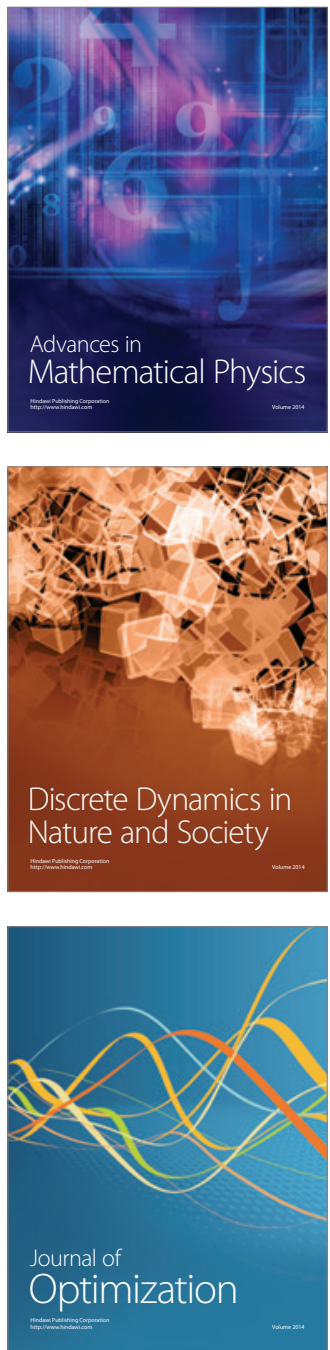